Bulletin de la Société Royale des Sciences de Liège, Vol. 85, 2016, p. 553 - 564

\title{
Investigating the effect of different opening types on steel plate shear wall behavior and finding the most critical condition
}

\author{
Ali Kheiri MARghZAR ${ }^{\mathrm{a}}$, Masoud Riyazi MAZLUMI ${ }^{\mathrm{b}}$, Amin Naseri POURYAZDI $^{\mathrm{a}}$ \\ ${ }^{a}$ M.Sc. in Structural engineering, Islamic Azad University of Mashhad, Department of Civil \\ engineering, Mashhad, Iran \\ ${ }^{\mathrm{b}}$ Assistant Professor, Islamic Azad University of Mashhad, Department of Civil engineering, \\ Mashhad, Iran
}

\begin{abstract}
In order to withstand lateral loads such as wind and seismic loads, various systems have been proposed so far. Among these, one of the latest one is steel plate shear wall system that has been used in several high and important buildings in different seismic zones of countries including the United State and Japan. Comparing to other lateral load resisting systems such as braces and concrete shear walls, the steel plate shear walls have relative advantages. Additionally, a number of studies and experiences indicate that this type of shear wall has considerable strength and stiffness compared to other systems.

Due to architectural requirements, openings are usually cut in panels of steel plate shear walls during construction. It is clear that the size and location of openings affect the performance of steel plate shear walls during earthquake. Therefore, two steel plate shear walls, one with stiffeners and other without stiffeners are considered and their performance are assessed under applying openings with different sizes. The shear walls are modeled in Abaqus and analyzed using finite element method to find the most critical opening size and location. For this reason, the entire plate of the shear wall is used; moreover, the forcedisplacement curves are obtained after the analysis to compare the shear walls performance.
\end{abstract}

Keywords: Steel plate shear wall, the most critical opening, strength, panel with and without stiffener

\section{Introduction}

Thus far, a number of various researches have been conducted in developed countries to study the structural strength of the shear walls. Most of these studies are theoretical which are accompanied by experimental findings to predict the behavior of steel plate shear walls better. However, there are some independent theoretical studies that have attempted to find more accurate designing principles for these shear walls. In experimental analyses, in some cases monotonic loading is applied to specimen and in other cases cyclic loading is used to simulate seismic loading. A number of studies conducted in Canada indicate that the system`s ductile behavior is accompanied by significant energy dissipation. In Japan, researchers have focused on stiffeners and steel plates with a lower yield point and proved that by utilizing them the system performance improves. The composite steel plate shear walls with slender plates were examined in the United Kingdom and United States, and the findings confirmed their significant post-bucking behavior. Some of these researches are mentioned in the following paragraphs.

Takanashi (1973), Nimura and Akiyama (1977) were the first researchers that conducted the experimental analysis on steel plate shear walls. Takanashi applied cyclic loading on 12 specimens in one and two-story shear walls. Yamada and Sugi (1992) published the results of their experiences on 14 specimens of steel plate shear walls under monotonic and cyclic loading. Turi (1996) studied the steel plate shear walls with low yielding point in high building. Driver (1998) also worked on a steal plate shear walls in 4-story building under cyclic loading. Furthermore, several researches have been conducted 
in this area by Aastaneh-Asl and Zhao in 2000 [1-9]. Sabouri Ghomi et al (2005) performed 16 experiments on steal panels under diagonal loading [10]. In United States, Elgaaly et al studied the behavior of steel plate shear walls. Their laboratory tests included applying horizontal cyclic loading on the roof part of six 3 -story, one-span structure which created under $14^{\text {th }}$ scale without stiffeners [11]. In addition, the steel plate shear walls were theoretically and experimentally studied by Berman and Bruneau et al. The experimental part included applying lateral cyclic loading on three 1-story, 1-span structures [12].

\section{Numerical analysis}

\subsection{Details of test specimens}

In Sabouri Ghomi study, two steel plate shear walls, one with stiffeners and other without stiffeners were analyzed under lateral loading (figure1 [13-14]). Here, the aim of this study is to conduct a more precise and comprehensive investigation on the effect of opening on steel plate shear walls performance.
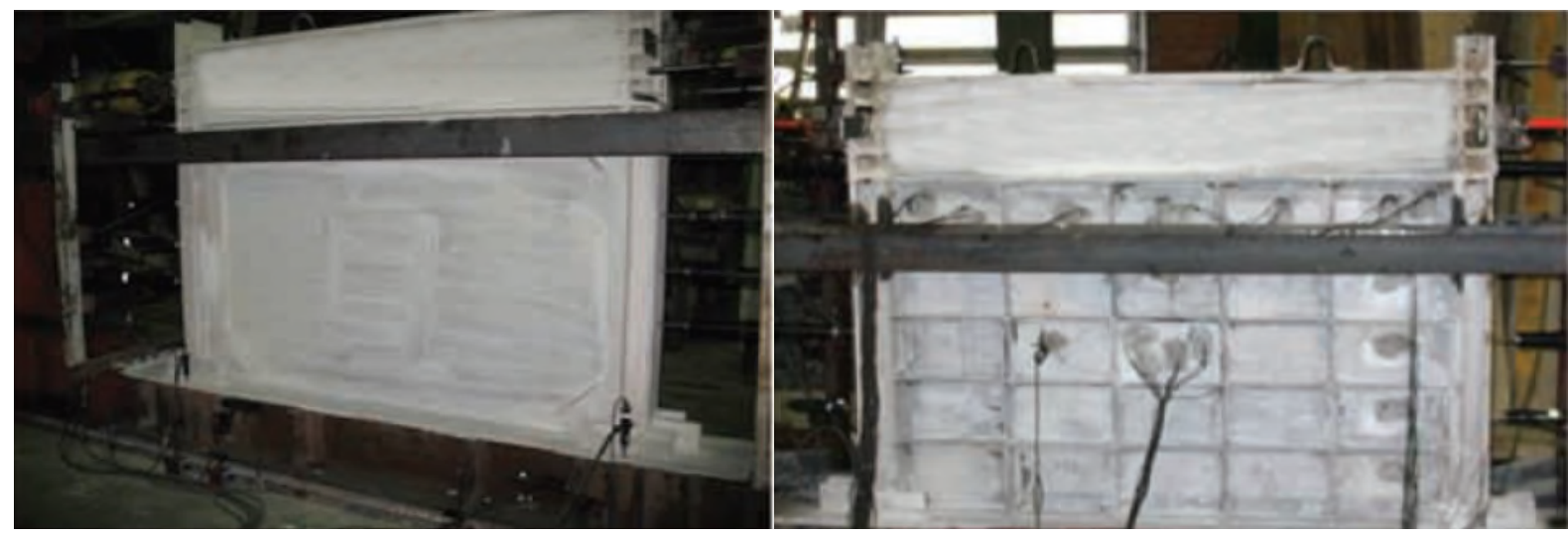

Fig. 1: The results obtained from Roberts and Sabouri

\subsection{Modeling}

Herein, the nonlinear static analysis is employed using the general-purpose finite element package. A steel plate, beam, column, and stiffener are modeled whose dimensions and characteristics are presented in table1. In Abaqus, the model is created using shell elements.

Table 1: Model dimension [13]

\begin{tabular}{llll}
\hline Member & Width $(\mathrm{mm})$ & Height $(\mathrm{mm})$ & Thickness $(\mathrm{mm})$ \\
\hline Shear wall panel & 1410 & 960 & 2 \\
Column stiffener & 90 & 140 & 3 \\
Vertical stiffener & 60 & 960 & 4 \\
Horizontal stiffener & 60 & 1410 & 4 \\
\hline
\end{tabular}

Table 2 shows the dimensions of the beam and columns while table 3 represents the characteristic of the steel plate shear walls. 
Bulletin de la Société Royale des Sciences de Liège, Vol. 85, 2016, p. 553 - 564

Table 2: Beam and column dimension [13]

\begin{tabular}{ccccc}
\hline Member & Flange width $(\mathrm{mm})$ & $\begin{array}{c}\text { Flange thickness } \\
(\mathrm{mm})\end{array}$ & Web height $(\mathrm{mm})$ & Web thickness (mm) \\
\hline Beam & 140 & 20 & 250 & 20 \\
Column & 140 & 15 & 60 & 20 \\
\hline
\end{tabular}

Table 3: Strength capacity of shear wall components [13]

\begin{tabular}{lll}
\hline Member & Yield stress (Mpa) & Ultimate stress (Mpa) \\
\hline Beam & 414.9 & 544 \\
Column & 414.9 & 544 \\
Shear wall panel & 192.4 & 288.7 \\
Stiffeners & 240 & 370 \\
\hline
\end{tabular}

\subsection{Validation of modeling results}

In this study, the generated model is analyzed under lateral loading to increase the failure load in the model. In order to prevent stress concentration, the shear stress is applied to the top of the model. All the connections are assigned to be rigid and the support of the lower part of the model is considered to be restrained. For validation the model, the force-displacement curves of the two specimens and the two generated model are compared (see figure 2 and 3 ).
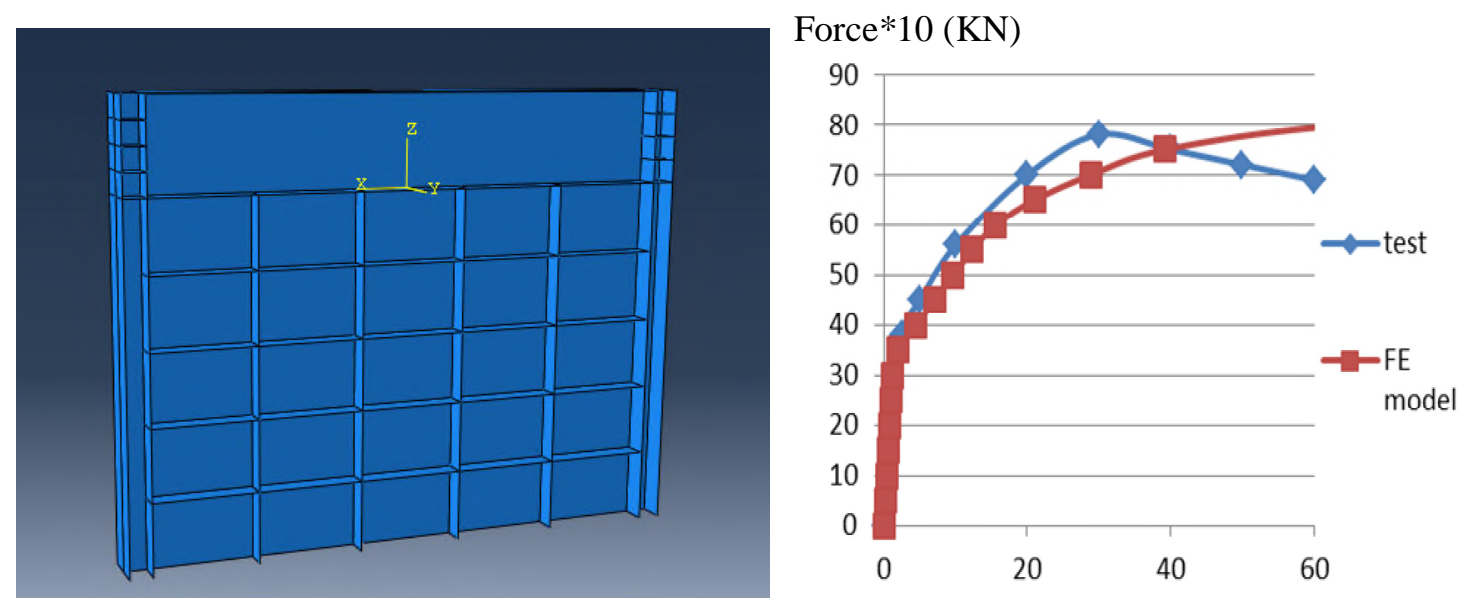

Displacement (mm)

Fig. 2: Comparison of the force-displacement curves of stiffened steel plate shear wall 

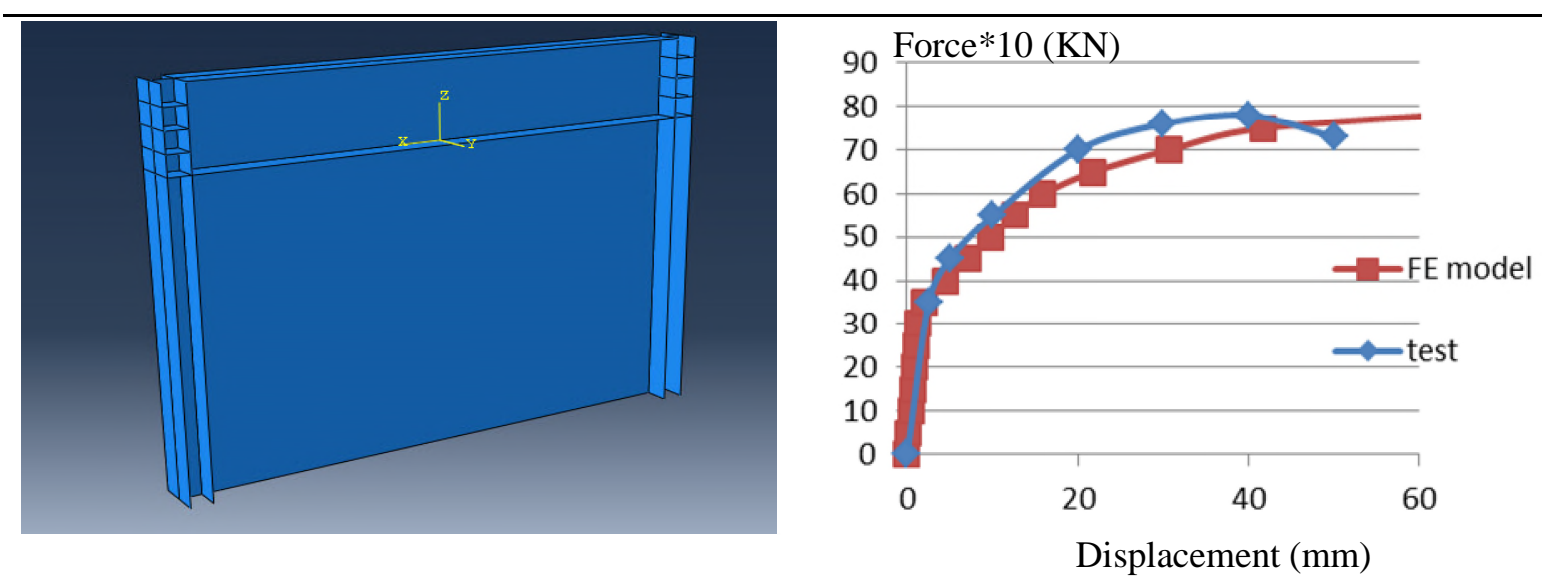

Fig. 3: Comparison of the force-displacement curves of unstiffened steel plate shear wall

\section{Effect of opening}

In this paper, openings with different size and location are used to investigate their effect on the behavior of steel plate shear walls. For this reason, the two mentioned shear walls (with and without stiffeners) with opening are analyzed to understand the shear wall behavior better. Five different openings are used with a ratio of $21 \%, 28 \%, 36 \%, 45 \%$ and $60 \%$. These percentages are the ratio of the openings width and height to the width and height of the steel plate shear walls. In table 4 , the size and location of these openings are presented. Henceforth, for ease of writing, the stiffened and unstiffened steel plate shear walls are abbreviated to SSPSW and USPSW, respectively. Figure 4 and 5 show the schematic characteristics of these opening that in total are 90 models. In the following, each one is discussed in detail.

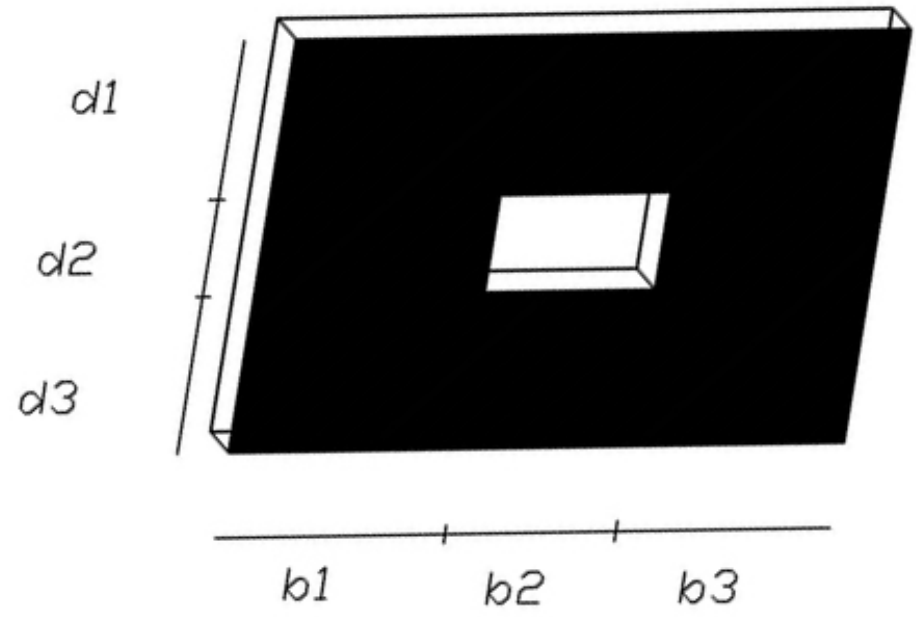

Fig. 4: Schematic figure of opening in steel plate shear wall 
Bulletin de la Société Royale des Sciences de Liège, Vol. 85, 2016, p. 553 - 564

In figure 5, the numbers represent the opening, for example, number 1 to 9 represent the opening created with a ratio of $27 \%$ in the entire plate of the shear walls. Moreover, the number 10 to 18 represent the openings with $28 \%$ ratio. The remaining numbers are also considered for $36 \%, 45 \%$ and $60 \%$. Eventually, for each shear wall (with and without stiffeners) there are 45 models which are discussed as follows.
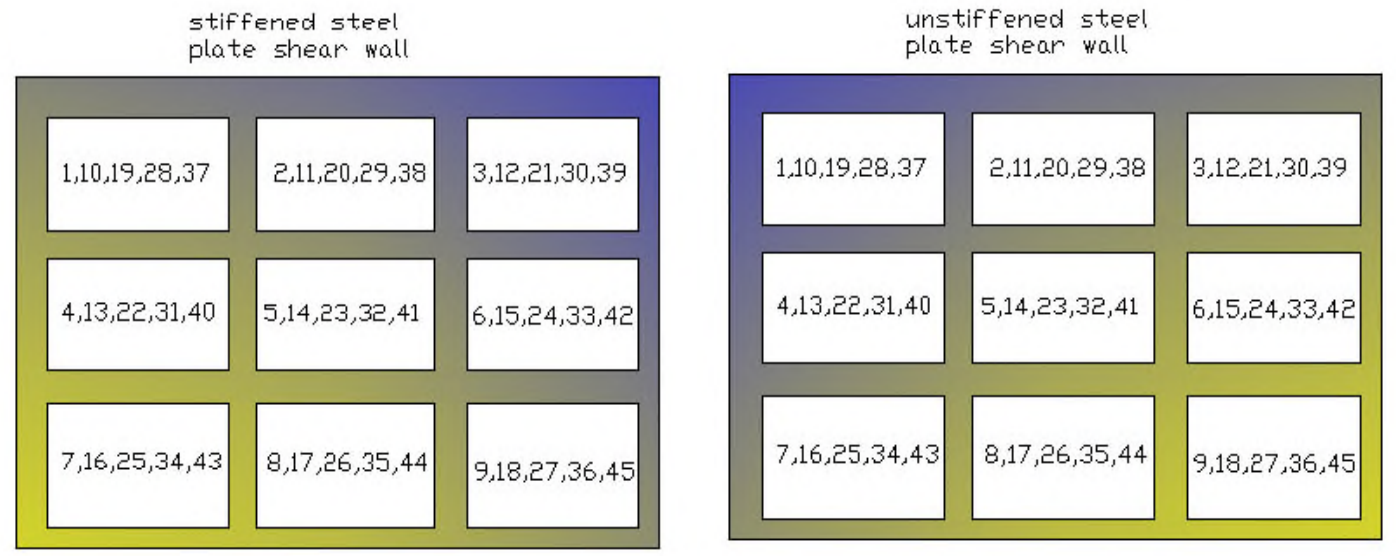

Fig. 5: Schematic figure of different opening types in steel plate shear wall

The size and placement of openings are presented in Table 4.

Table 4: Size and location of openings in steel plate shear wall

\begin{tabular}{|c|c|c|c|c|c|c|c|c|}
\hline $\begin{array}{c}\text { Opening } \\
\text { ratio }\end{array}$ & $\begin{array}{c}\text { Panels with } \\
\text { un stiffened } \\
\text { plates }\end{array}$ & $\begin{array}{c}\text { Panels with } \\
\text { stiffened } \\
\text { plates }\end{array}$ & $\mathrm{b} 1(\mathrm{~mm})$ & $\mathrm{b} 2(\mathrm{~mm})$ & $\mathrm{b} 3(\mathrm{~mm})$ & $\mathrm{d} 1(\mathrm{~mm})$ & $\mathrm{d} 2(\mathrm{~mm})$ & $\mathrm{d} 3(\mathrm{~mm})$ \\
\hline $21 \%$ & USPSWO-1 & SSPSWO-1 & 40 & 300 & 1070 & 40 & 200 & 720 \\
\hline $21 \%$ & USPSWO-2 & SSPSWO-2 & 555 & 300 & 555 & 40 & 200 & 720 \\
\hline $21 \%$ & USPSWO-3 & SSPSWO-3 & 1070 & 300 & 40 & 40 & 200 & 720 \\
\hline $21 \%$ & USPSWO-4 & SSPSWO-4 & 40 & 300 & 1070 & 380 & 200 & 380 \\
\hline $21 \%$ & USPSWO-5 & SSPSWO-5 & 555 & 300 & 555 & 380 & 200 & 380 \\
\hline $21 \%$ & USPSWO-6 & SSPSWO-6 & 1070 & 300 & 40 & 380 & 200 & 380 \\
\hline $21 \%$ & USPSWO-7 & SSPSWO-7 & 40 & 300 & 1070 & 720 & 200 & 40 \\
\hline $21 \%$ & USPSWO-8 & SSPSWO-8 & 555 & 300 & 555 & 720 & 200 & 40 \\
\hline $21 \%$ & USPSWO-9 & SSPSWO-9 & 1070 & 300 & 40 & 720 & 200 & 40 \\
\hline $28 \%$ & USPSWO-10 & SSPSWO-10 & 40 & 395 & 975 & 40 & 270 & 650 \\
\hline $28 \%$ & USPSWO-11 & SSPSWO-11 & 507.5 & 395 & 507.5 & 40 & 270 & 650 \\
\hline $28 \%$ & USPSWO-12 & SSPSWO-12 & 975 & 395 & 40 & 40 & 270 & 650 \\
\hline $28 \%$ & USPSWO-13 & SSPSWO-13 & 40 & 395 & 975 & 345 & 270 & 345 \\
\hline $28 \%$ & USPSWO-14 & SSPSWO-14 & 507.5 & 395 & 507.5 & 345 & 270 & 345 \\
\hline $28 \%$ & USPSWO-15 & SSPSWO-15 & 975 & 395 & 40 & 345 & 270 & 345 \\
\hline $28 \%$ & USPSWO-16 & SSPSWO-16 & 40 & 395 & 975 & 650 & 270 & 40 \\
\hline $28 \%$ & USPSWO-17 & SSPSWO-17 & 507.5 & 395 & 507.5 & 650 & 270 & 40 \\
\hline $28 \%$ & USPSWO-18 & SSPSWO-18 & 975 & 395 & 40 & 650 & 270 & 40 \\
\hline $36 \%$ & USPSWO-19 & SSPSWO-19 & 40 & 520 & 850 & 40 & 350 & 570 \\
\hline $36 \%$ & USPSWO-20 & SSPSWO-20 & 445 & 520 & 445 & 40 & 350 & 570 \\
\hline $36 \%$ & USPSWO-21 & SSPSWO-21 & 850 & 520 & 40 & 40 & 350 & 570 \\
\hline $36 \%$ & USPSWO-22 & SSPSWO-22 & 40 & 520 & 850 & 305 & 350 & 305 \\
\hline
\end{tabular}


Bulletin de la Société Royale des Sciences de Liège, Vol. 85, 2016, p. 553 - 564

\begin{tabular}{|c|c|c|c|c|c|c|c|c|}
\hline $36 \%$ & USPSWO-23 & SSPSWO-23 & 445 & 520 & 445 & 305 & 350 & 305 \\
\hline $36 \%$ & USPSWO-24 & SSPSWO-24 & 850 & 520 & 40 & 305 & 350 & 305 \\
\hline $36 \%$ & USPSWO-25 & SSPSWO-25 & 40 & 520 & 850 & 570 & 350 & 40 \\
\hline $36 \%$ & USPSWO-26 & SSPSWO-26 & 445 & 520 & 445 & 570 & 350 & 40 \\
\hline $36 \%$ & USPSWO-27 & SSPSWO-27 & 850 & 520 & 40 & 570 & 350 & 40 \\
\hline $45 \%$ & USPSWO-28 & SSPSWO-28 & 40 & 634.5 & 735.5 & 40 & 432 & 488 \\
\hline $45 \%$ & USPSWO-29 & SSPSWO-29 & 387.75 & 634.5 & 387.75 & 40 & 432 & 488 \\
\hline $45 \%$ & USPSWO-30 & SSPSWO-30 & 735.5 & 634.5 & 40 & 40 & 432 & 488 \\
\hline $45 \%$ & USPSWO-31 & SSPSWO-31 & 40 & 634.5 & 735.5 & 264 & 432 & 264 \\
\hline $45 \%$ & USPSWO-32 & SSPSWO-32 & 387.75 & 634.5 & 387.75 & 264 & 432 & 264 \\
\hline $45 \%$ & USPSWO-33 & SSPSWO-33 & 735.5 & 634.5 & 40 & 264 & 432 & 264 \\
\hline $45 \%$ & USPSWO-34 & SSPSWO-34 & 40 & 634.5 & 735.5 & 488 & 432 & 40 \\
\hline $45 \%$ & USPSWO-35 & SSPSWO-35 & 387.75 & 634.5 & 387.75 & 488 & 432 & 40 \\
\hline $45 \%$ & USPSWO-36 & SSPSWO-36 & 735.5 & 634.5 & 40 & 488 & 432 & 40 \\
\hline $60 \%$ & USPSWO-37 & SSPSWO-37 & 40 & 846 & 524 & 40 & 576 & 344 \\
\hline $60 \%$ & USPSWO-38 & SSPSWO-38 & 282 & 846 & 282 & 40 & 576 & 344 \\
\hline $60 \%$ & USPSWO-39 & SSPSWO-39 & 524 & 846 & 40 & 40 & 576 & 344 \\
\hline $60 \%$ & USPSWO-40 & SSPSWO-40 & 40 & 846 & 524 & 192 & 576 & 192 \\
\hline $60 \%$ & USPSWO-41 & SSPSWO-41 & 282 & 846 & 282 & 192 & 576 & 192 \\
\hline $60 \%$ & USPSWO-42 & SSPSWO-42 & 524 & 846 & 40 & 192 & 576 & 192 \\
\hline $60 \%$ & USPSWO-43 & SSPSWO-43 & 40 & 846 & 524 & 344 & 576 & 40 \\
\hline $60 \%$ & USPSWO-44 & SSPSWO-44 & 282 & 846 & 282 & 344 & 576 & 40 \\
\hline $60 \%$ & USPSWO-45 & SSPSWO-45 & 524 & 846 & 40 & 344 & 576 & 40 \\
\hline
\end{tabular}

After simulating and analyzing the models regarding the mentioned characteristics, the forcedisplacement curves are obtained (see figure 6 to 10). Firstly, for the unstiffened steel plate shear walls:

Force*10 $(\mathrm{KN})$

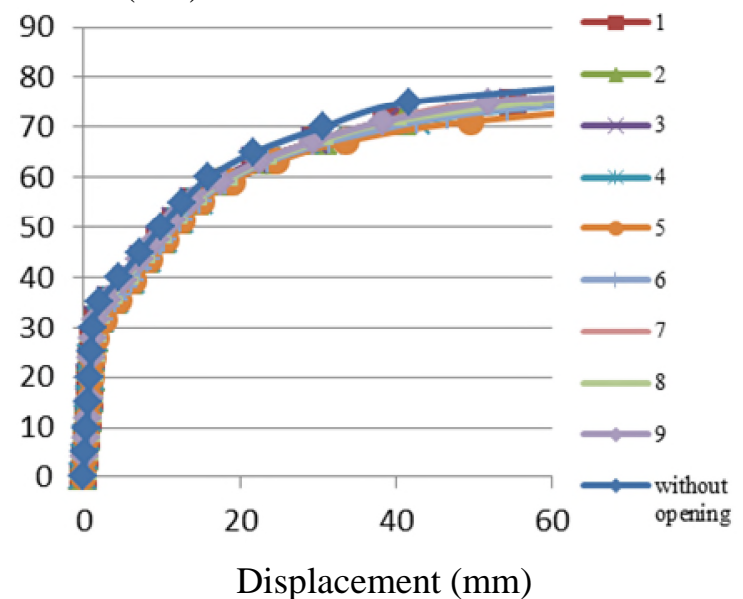

Fig. 6: Force-displacement curves of opening in unstiffened steel plate shear wall with a ratio of $21 \%$ Force*10 $(\mathrm{KN})$
Force*10 $(\mathrm{KN})$

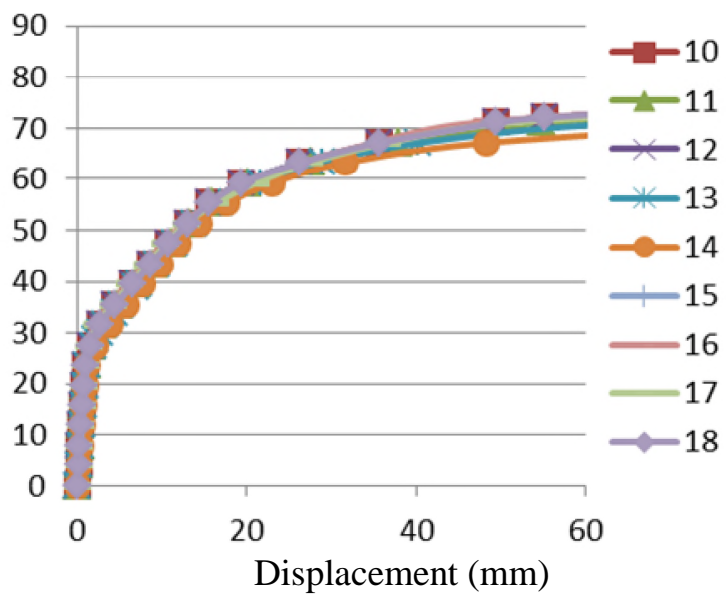

Fig. 7: Force-displacement curves of opening in unstiffened steel plate shear wall with a ratio of $28 \%$

Force*10 (KN) 
Bulletin de la Société Royale des Sciences de Liège, Vol. 85, 2016, p. 553 - 564

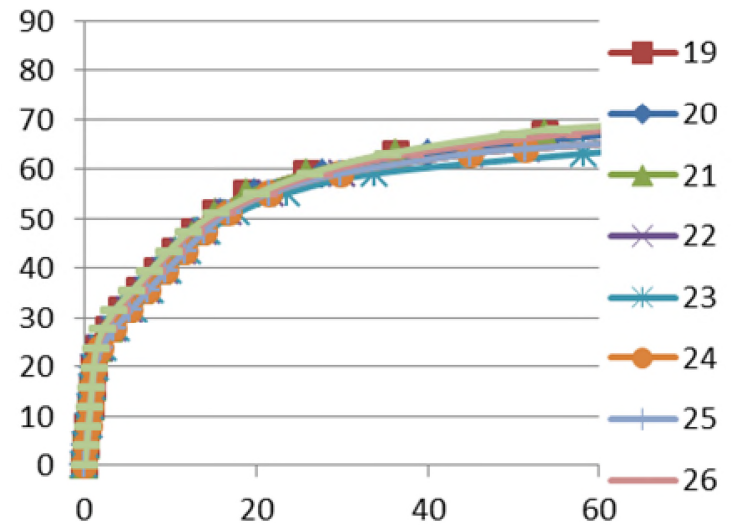

Displacement (mm)

Fig. 8: . Force-displacement curves of opening in unstiffened steel plate shear wall with a ratio of $36 \%$

Force*10 $(\mathrm{KN})$

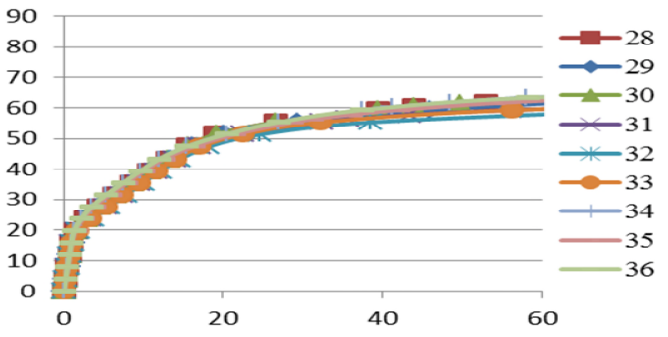

Displacement (mm)

Fig. 9: Force-displacement curves of opening in unstiffened steel plate shear wall with a ratio of $45 \%$

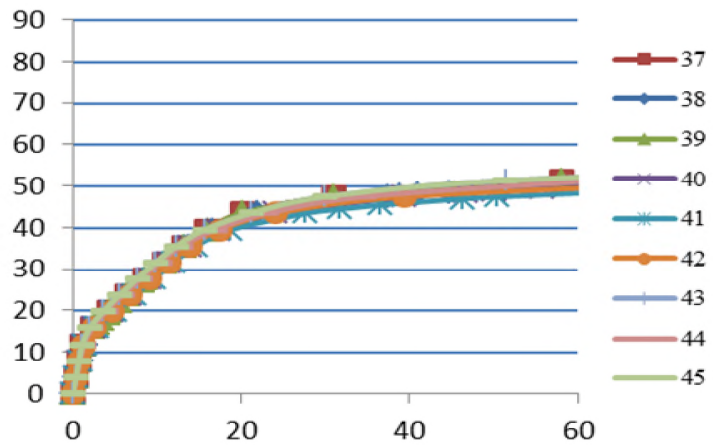

Fig. 10: Force-displacement curves of opening in unstiffened steel plate shDisplacementatimond0\%

Then, the force-displacement curves for stiffened steel plate shear wall are presented (see figure 11 to $15)$.

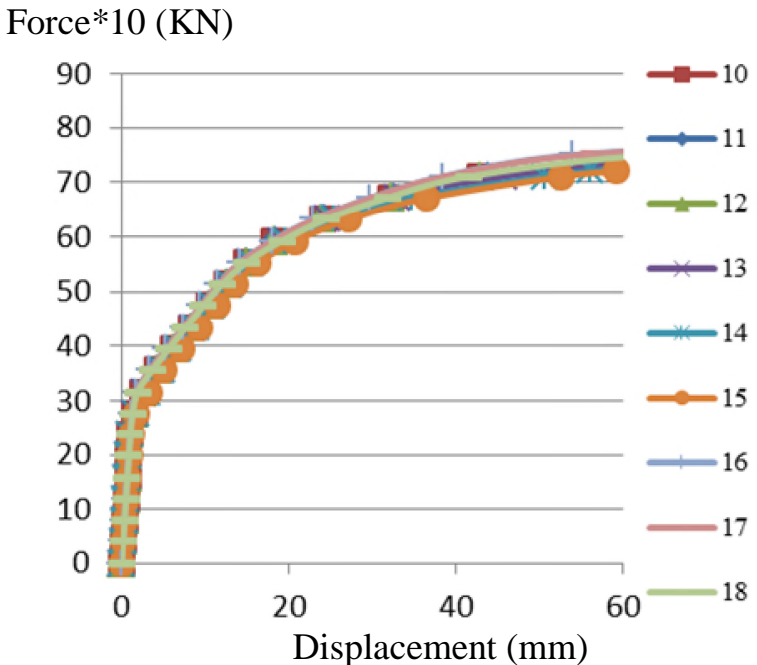

Fig. 11: Force-displacement curves of opening in stiffened steel plate shear wall with a ratio of $21 \%$
Force*10 $(\mathrm{KN})$

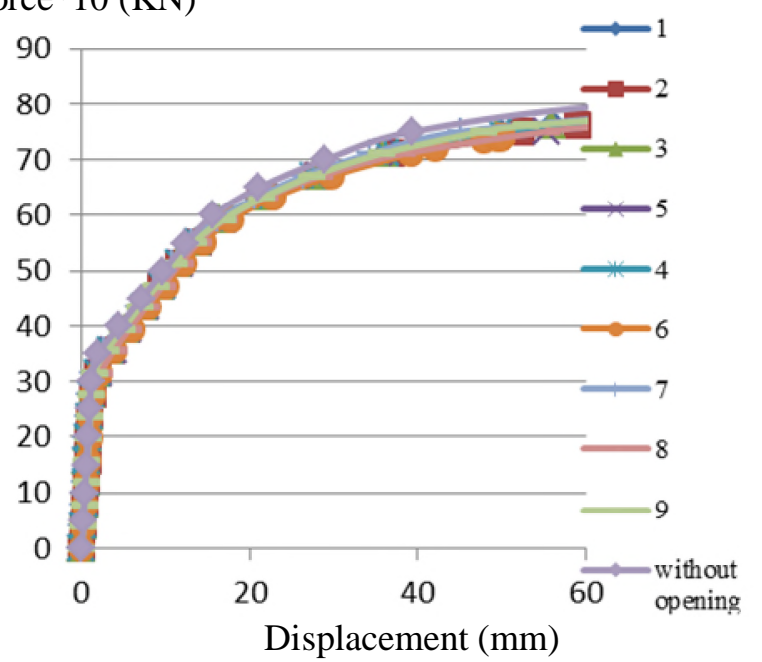

Fig. 12: Force-displacement curves of opening in stiffened steel plate shear wall with a ratio of $28 \%$ 


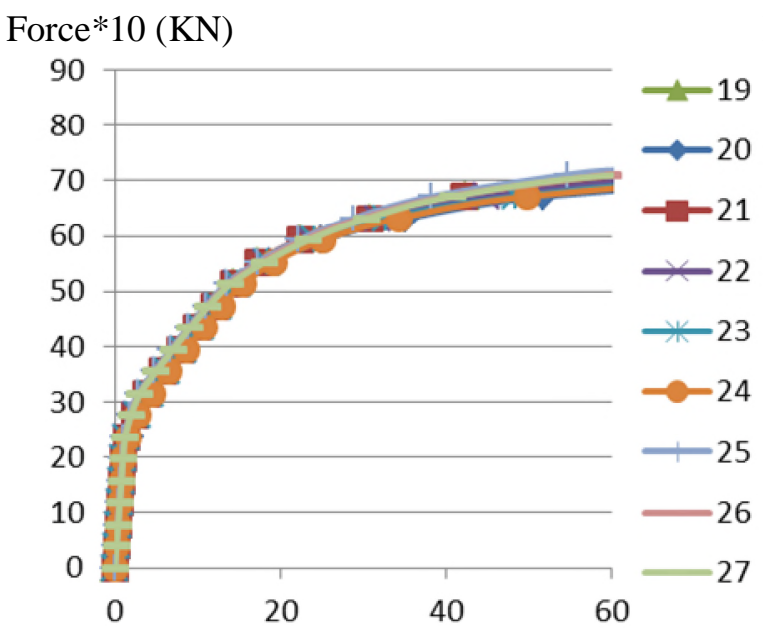

Displacement (mm)

Fig. 13: Force-displacement curves of opening in stiffened steel plate shear wall with a ratio of $36 \%$
Force ${ }^{* 10}(\mathrm{KN})$

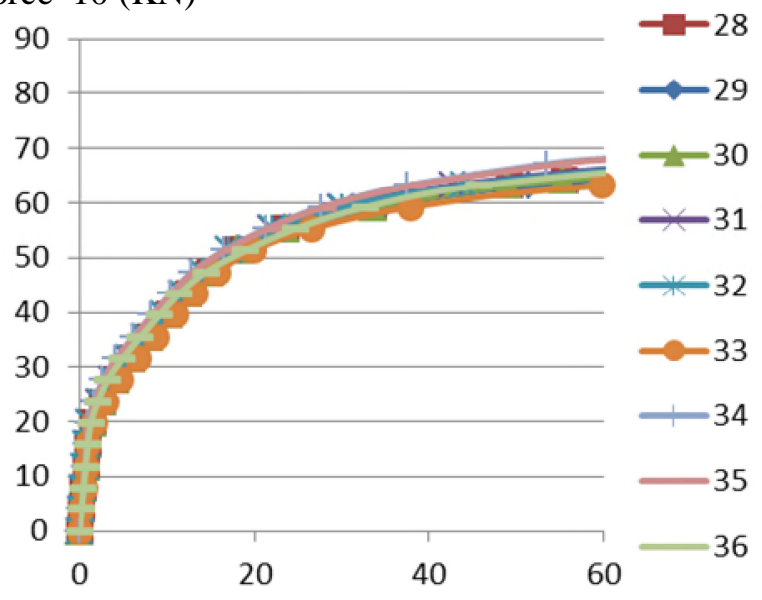

Displacement (mm)

Fig. 14: Force-displacement curves of opening in stiffened steel plate shear wall with a ratio of $45 \%$

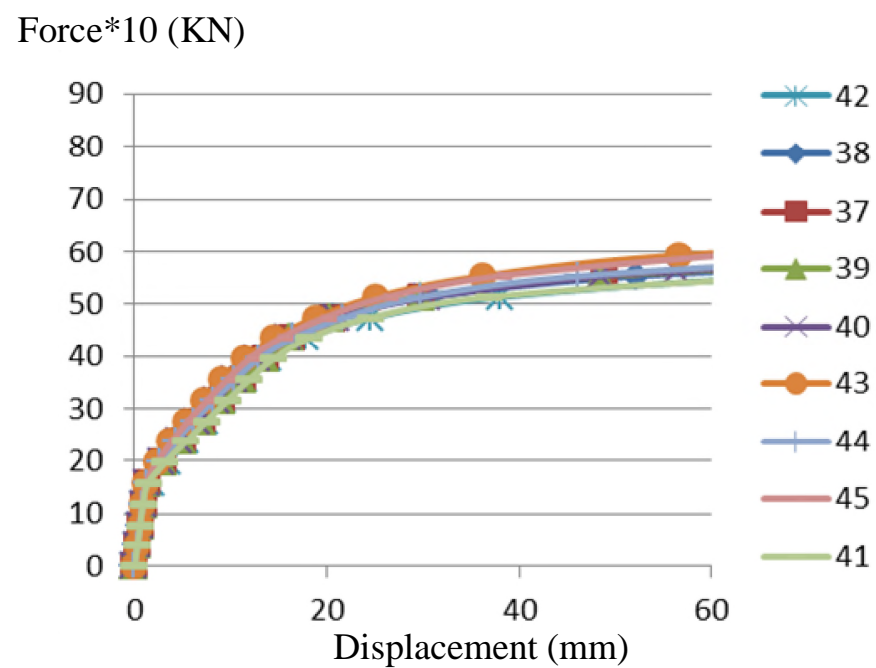

Fig. 15: Force-displacement curves of opening in stiffened steel plate shear wall with a ratio of $60 \%$

\section{4. the most critical opening}

Locating the critical opening is a matter of great concern in our design. When a horizontal force is applied to a structure, the compressive diagonal of the shear wall plate is the most vulnerable part. Since the bucking in the middle of the mentioned structure reaches its highest level, this area can be regarded as the most critical part. Considering these two factors, it can be concluded that the opening 5, 14, 23, 32, and 41 generated in the middle part of the shear wall are the critical one which can be proved by the curves presented in the previous section. It can be seen that by increasing the opening size, the structure bearing capacity will reduce (see Fig. 16 and 17). 


\section{Force*10 $(\mathrm{KN})$}

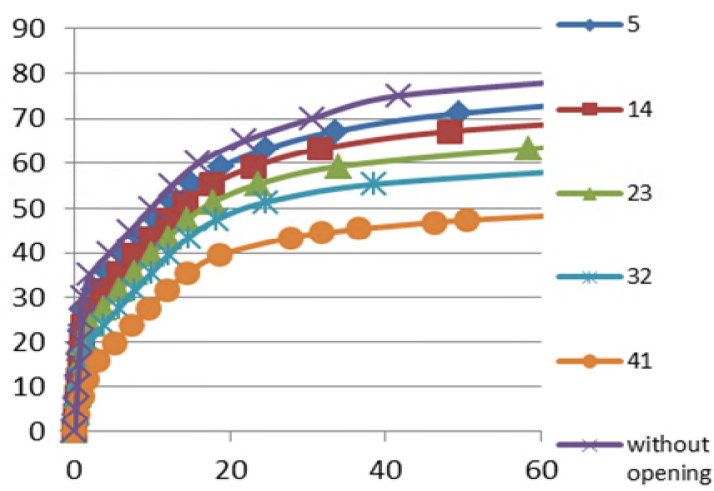

Displacement (mm)

Fig. 16: SSPSWO (5-14-23-32-41)

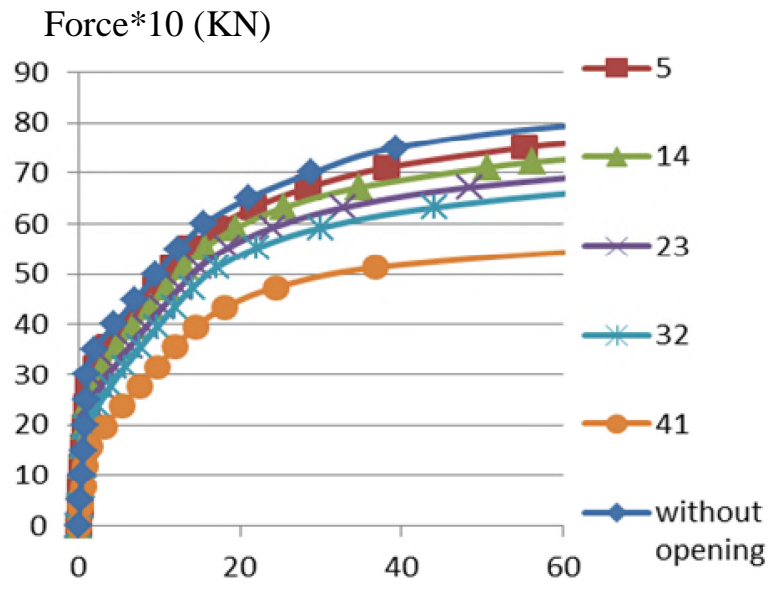

Displacement (mm)

Fig. 17: USPSWO (5-14-23-32-41)

In the stiffened steel plate shear wall, the longitudinal and transverse stiffeners considerably prevent the buckling. Such an advantage increases the bearing capacity of the structure. (See figure 18 to 21).

Force*10 $(\mathrm{KN})$

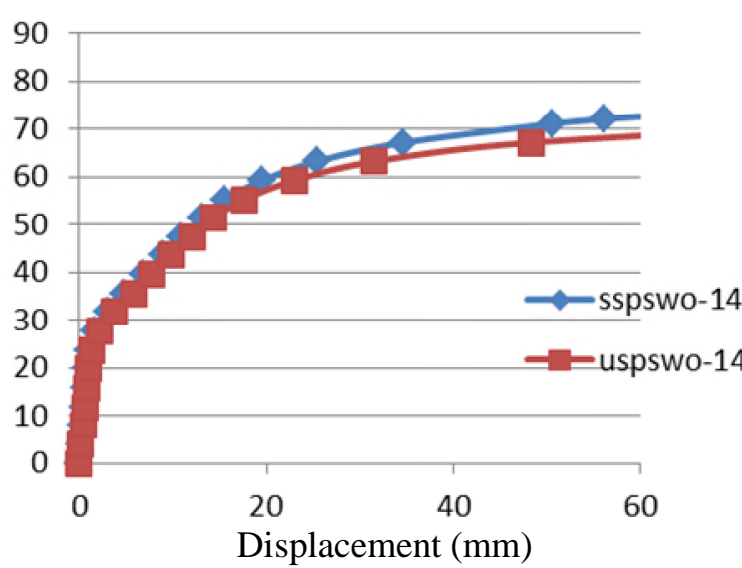

Fig. 19: (U-S)SPSWO14

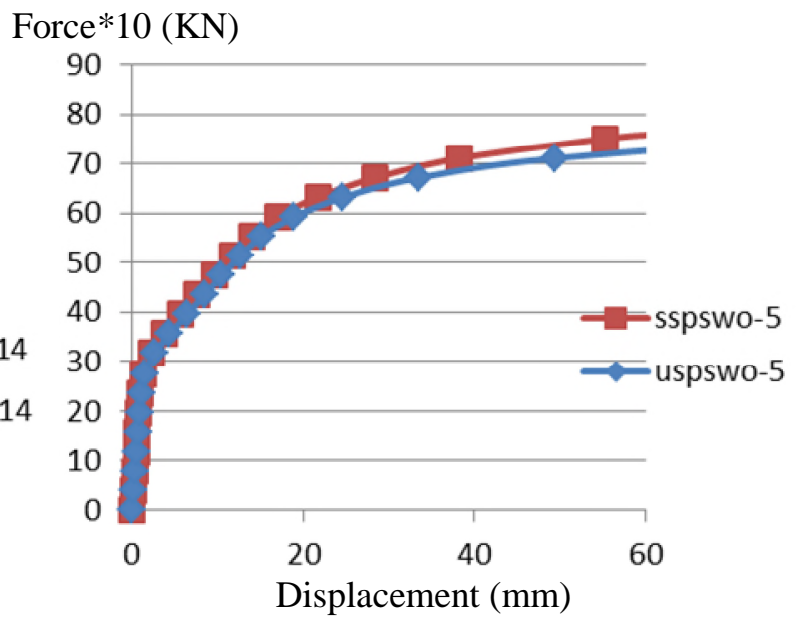

Fig. 18: (U-S) SPSWO5 
Bulletin de la Société Royale des Sciences de Liège, Vol. 85, 2016, p. 553 - 564

Force*10 $(\mathrm{KN})$

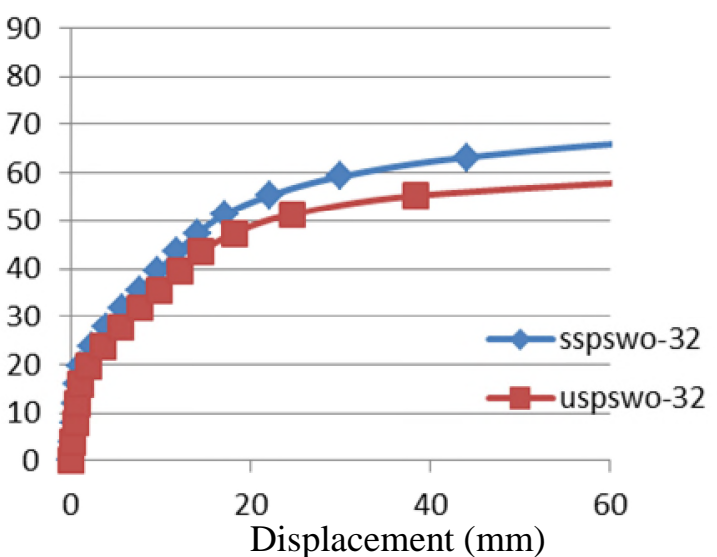

Fig. 20: (U-S)
Force*10 $(\mathrm{KN})$

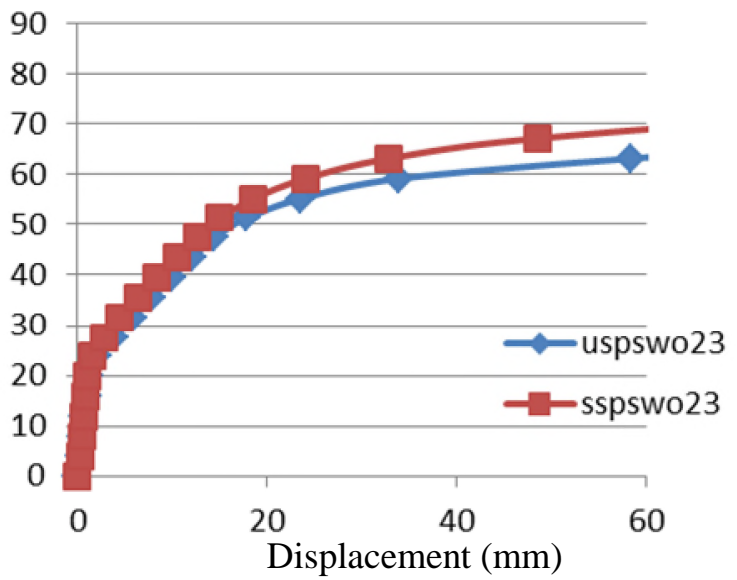

Fig. 21: (U-S) SPSWO23

In the USPSW diagram indicated in figure 22, the horizontal axis is the ratio of the opening width to the width of the shear wall panel $\left(b_{2} / b\right)$ and the vertical axis is the ratio of the maximum bearing capacity of the structure with opening to the bearing capacity of the structure without opening $\left(\mathrm{F} / \mathrm{F}_{\mathrm{u}}\right)$. It is clear that the horizontal axis represents the number of $21 \%, 28 \%, 36 \%, 45 \%$ and $60 \%$ and for each ratio 9 openings are considered whose $\mathrm{F} / \mathrm{F}_{\mathrm{u}}$ ratios are represented in vertical axis. In this diagram, it can be seen that the force reduces while the size of the opening increases. This reduction can be represented relatively by a line $\left(1-b_{2} / b\right)$ which is a good and conservative approximation.

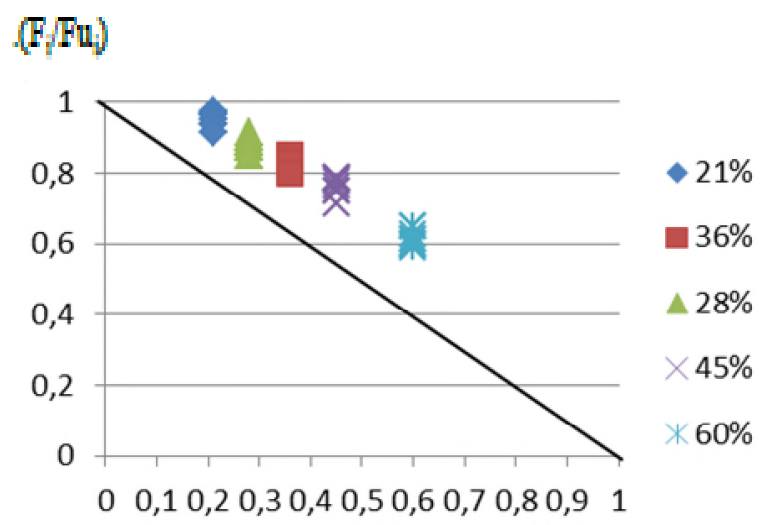

$\left(\mathrm{b}_{\mathrm{i}} / \mathrm{b}\right)$

Displacement $(\mathrm{mm})$

Fig. 22: Force-opening dimension relationship (As the dimension of opening increases, the shear force begins to decrease)

\section{Conclusion}

Based on previous studies, this system has demonstrated its significant ductility due to its continuity. Furthermore, regarding its strength and stiffness, it can dissipate huge amount of energy. In some cases, based on economic analysis, this system saves about $50 \%$ of costs. Furthermore, it can be easily installed in a way that it is possible to make any openings in it with various dimensions. In case that the walls strength and stiffness become insufficient, it can be strengthened by using stiffeners around the opening. 
Bulletin de la Société Royale des Sciences de Liège, Vol. 85, 2016, p. 553 - 564

Here, it can be concluded that compared to other systems, since it has relatively considerable advantages, the steel plate shear wall system can be a credible alternative to other lateral load resisting systems (braces and concrete shear wall) against seismic loads (wind and earthquake), if it is accurately designed and constructed.

In summary, the obtained results are as follows:

1. The findings indicate that by increasing the openings' dimension, the bearing capacity of the system is reduced. Moreover, employing stiffeners which increase the strength can reduce the ductility of the steel plate shear wall.

2. In the design procedure of these systems, the middle part of steel plate shear walls is the critical area; therefore, the openings should be generated in other areas rather than the central part. Such an approach is an acceptable and conservative view that should be considered in design and construction of steel plate shear walls.

3. The main finding of this research is about the effect of force reduction resulted from the increase in opening size which is considered in designing procedure of these structures. As it was mentioned before, if the horizontal axis is the ratio of the opening width to the width of the shear wall panel $\left(b_{2} / b\right)$ and the vertical axis is the ratio of the maximum bearing capacity of the structure with opening to the bearing capacity of the structure without opening $\left(\mathrm{F} / \mathrm{F}_{\mathrm{u}}\right)$, and the changes are in the linear form; the reduction can be represented relatively by a line $\left(1-b_{2} / b\right)$ which is a good and conservative approximation.

\section{References}

[1] Astaneh-Asl، A. Seismic Behavior and Design of steel shear walls، Paper Distributed and presented at the 2001 SEOANC Seminar, Structural Engineers Assoc. of Northern California, November 7, 2001, San Francisco.

[2] F. Hatami Bargh, M. Ragheb, Ductility of slender steel plate shear wall and comparison between the behavior of stiffened and ustiffened steel plate shear walls, Journal of Tabriz Engineering Faculty, University of Tabriz, 33 (3) (2006) 43-48.

[3] Sabbeli، R. and Bruneau، M. Steel plate shear walls‘ American institute of steel construction، 2007.

[4] M. Bagheriye, Ch. Gheyratmand, S. Tarvardilo, The effect of opening on the stiffness and strength of steel plate shear wall and its modeling with equivalent brace, International Conference on Light Weight Construction and Earthquake, Jahad Daneshgahi, Kerman, (2010).

[5] Timler، P.A and Kulak، G.L، Experimental study of steel plate shear walls، Department of civil engineering the University of Alberta، 1983.

[6] Thorburn, L.J., Kulak, G.L., and Montgomery, C.J., "Analysis of Steel Plate Shear Walls", Structural Engineering Report No. 107, Department of Civil Engineering, Universtiy of Alberta, Edmonton, Alberta, Canada (1983).

[7] Roberts، T .M.، "Seismic resistance of steel plate shear walls" ، Engineering structures، Vol. 17، No. 5، pp.344-351، 1995 .

[8] Bruneau، M. Berman، J.، Garcia، D.L.and Vian‘ D.، A review of steel plate shear wall design requirements and research، north American steel construction conference، ENGINEERING JOURNAL ، FIRST QUARTER، pp. 27-34، 2005.

[9] R. Rahgozar, F. Yahya Abadi, Lateral bracing in steel moment frame based on performance level, International Conference on Light Weight Construction and Earthquake, Jahad Daneshgahi, Kerman, (2010). 
[10] Sabouri-Ghomi، S. and Sajjadi، S.R.، "Experimental and theoretical studies of steel plate shear walls with and without stiffeners" Journal of constructional steel research، No. 75، pp.152-159، 2012.

[11] Elgaaly، M.، "Thin steel plate shear walls behavior and analysis "، Thin-Walled structures، No. 32، pp. 151-180، 1998.

[12] Bruneau, M., Berman, J.W., Lopez-Garcia, D., and Vian, D. (2007) "A Review of Steel Plate Shear Wall Design Requirements and Research” Engineering Journal, AISC, Vol. 44, No. 1, pp. 27-34.

[13] Sabouri-Ghomi، S.، Ahouri، E.`Sajadi، R.، Alavi، M. Roufegarinejad‘ A. and Bradford، M.A، "Stiffness and strength degradation of steel shear walls having an arbitrarily-located opening"Journal of construnctional steel research، No. 79، pp. 91-100، 2012.

[14] Sabouri S، Asad Sajadi R. Experimental study of seismic behavior factor and energy absorption of ductile steel plate shear walls with and without opening. J. Steel Structure، Vol. 4، No. 3، pp.12-25، 2012. 